\title{
ENVIRONMENT, ENERGY AND SUSTAINABLE DESIGN: BUILDINGS AND URBAN SPACES
}

\author{
Joana Carla Soares Gonçalves
}

Figura 1: Palestra do professor Simos Yannas. Crédito: Foto de Denise Duarte
Trata-se do relato do workshop "Environment, Energy and Sustainable Design: Buildings and Urban Spaces", com a participação do professor visitante do Programa de Pós-Graduação da Faculdade de Arquitetura e Urbanismo da Universidade de São Paulo, doutor Simos Yannas, vinculado à Architectural Association Graduate School, de Londres. O evento da área de concentração em Tecnologia da Arquitetura contou com o apoio do Departamento de Tecnologia e do Laboratório de Conforto Ambiental e Eficiência Energética, organizado pelas professoras Joana Gonçalves, Anésia Frota e Denise Duarte no período de 23 a 28 de novembro de 2006, tendo como participantes professores e alunos de graduação e pós-graduação da FAUUSP, e aberto aos demais interessados.

Simos Yannas é diretor do Programa de Pós-Graduação Environment and Energy da Architecture Association Graduate School desde 1979 e coordenador acadêmico do programa de doutorado da AA Graduate School desde 2004. Estudou arquitetura na École Polytechnique, Lausanne, na National Technical University, em Atenas, graduando-se na Architectural Association School of

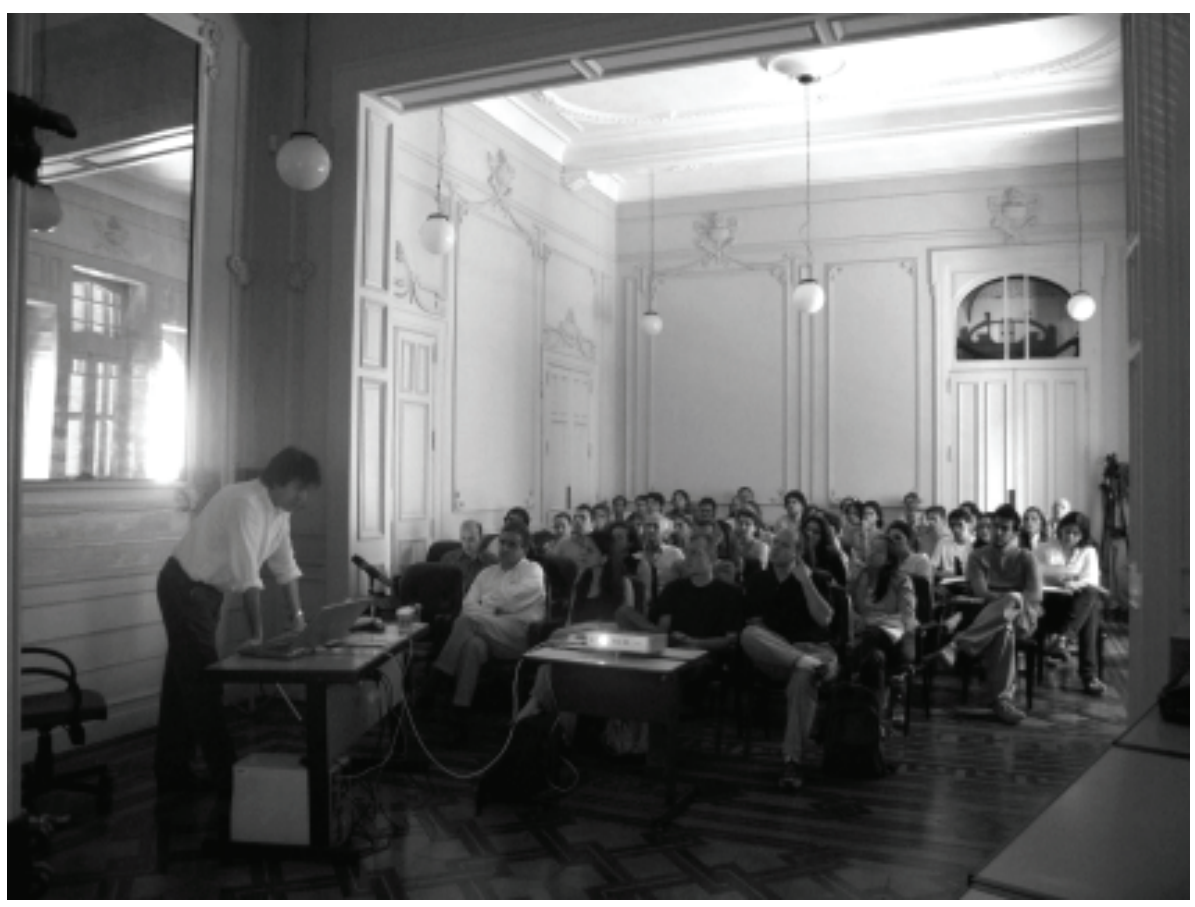


Architecture, em Londres. Seu doutorado tratou do tema da eficiência energética em habitações no Reino Unido. De suas diversas publicações, as duas mais recentes são: Roof cooling techniques: A design handbook, publicado em 2005, com apoio da Comunidade Européia; e Em busca de uma arquitetura sustentável para os trópicos, publicado no Rio de Janeiro em 2004, com apoio da Fundação Carlos Chagas Filho de Amparo à Pesquisa do Estado do Rio de Janeiro Faperj, e com auxílios da Capes e do CNPq para a realização do projeto.

O Programa de Pós-Graduação Environment and Energy Studies, caracterizado por reunir alunos de todo o mundo, ano após ano, incluindo brasileiros, oferece duas opções de mestrado, o MSc (Master of Science) e MAarch (Master of Architecture). Estando na vanguarda da discussão sobre o ensino em conforto ambiental e eficiência energética no ambiente construído em pós-graduação, o programa conta com a colaboração de renomados profissionais e pesquisadores e uma rede de ferramentas avançadas de simulação computacional, para a pesquisa em conforto ambiental e eficiência energética na arquitetura e no desenho urbano.

\section{O EVENTO}

A visita do professor Simos Yannas à FAUUSP em novembro de 2006, para o workshop "Environment, Energy and Sustainable Design: Buildings and Urban Spaces" reuniu pesquisadores e alunos de pós-graduação e graduação em arquitetura e urbanismo para refletir sobre questões metodológicas e técnicas do conforto ambiental e da eficiência energética no projeto de arquitetura e espaços abertos. Nesse sentido, o professor Yannas foi convidado para falar de suas pesquisas, das quais fazem parte estudos de caso no Rio de Janeiro (em colaboração com a pós-graduação da Faculdade de Arquitetura da Universidade Federal do Rio de Janeiro), assim como de sua abordagem didática nos cursos de mestrado que dirige, com destaque para os exercícios de projeto e o uso de ferramentas de simulação computacional.

Ao lado do professor visitante, professores do Departamento de Tecnologia da Arquitetura dessa faculdade participaram com apresentação de palestras relacionadas ao tema. Nesse contexto, foram trazidos para a discussão resultados de pesquisa cobrindo questões como: o cenário nacional de consumo de energia em edifícios, estudos de caso brasileiros de projetos desenvolvidos segundo parâmetros de uma arquitetura bioclimática e, ainda, o ensino de conforto ambiental na FAUUSP. Complementando a programação do workshop, foram realizados seminários sobre os trabalhos de pesquisa dos alunos da pósgraduação, vinculados ao Laboratório de Conforto Ambiental e Eficiência Energética, LABAUT, com apreciação crítica do professor Simos Yannas.

Durante o período do workshop, o professor visitante ministrou quatro palestras intituladas: "Environment and Energy in Buildings: Design Principles for Sustainable Solutions and Case Studies" (Ambiente e energia em edifícios: Princípios de projeto para uma arquitetura mais sustentável, estudos de caso); "Outdoor Spaces and Urban Microclimates: Towards more Sustainable Cities" (Espaços abertos e microclimas urbanos: Em direção a cidades mais 
sustentáveis); "Roof Cooling Techniques: Design Solutions for Environmental Design" (Estratégias de resfriamento de coberturas: Soluções para projetos bioclimáticos); e "Design Techniques and Support Tools for Sustainable Architecture and Urban Design", (Técnicas de projeto e ferramentas para a arquitetura e o desenho urbano sustentável).

$\mathrm{Na}$ abertura do workshop, o professor Yannas falou sobre o objetivo e a didática do Programa de Pós-Graduação Environment and Energy, o qual prima por formar arquitetos inovadores, acreditando que o tema da arquitetura sustentável traz novos horizontes para o ensino e a prática arquitetônica. Assim, cada ano acadêmico é um experimento pedagógico diferenciado, parte de um processo evolutivo de estudo das relações entre forma arquitetônica, materialidade e desempenho ambiental.

Nesse contexto, o exercício de projeto é um meio eficiente de os alunos apreenderem os princípios da física aplicada à arquitetura e, paralelamente, treinarem a aplicação das ferramentas de simulação computacional, direcionadas aos estudos de conforto ambiental e eficiência energética. A maioria dos trabalhos aborda as questões ambientais na escala do projeto urbano, antes de lidar com o edifício. Nas etapas iniciais dos estudos de projeto, os alunos trabalham com modelos físicos, uma vez que essa é uma linguagem conhecida dos arquitetos os quais chegam para o programa; porém, com o desenvolvimento dos projetos, os alunos são lançados à modelagem digital do desempenho ambiental.

Dentro das premissas do programa, é cobrada dos alunos criatividade nas respostas aos desafios do desempenho ambiental, mais do que qualquer compromisso com a construtibilidade. Segundo a experiência do professor Yannas, dessa maneira os alunos adquirem conhecimento técnico sobre o tema. O estudo detalhado do legado arquitetônico, com exemplos de sucesso e insucesso quanto ao desempenho ambiental, tem sido outra vertente importante do curso, com a finalidade de auxiliar os alunos na formação de uma crítica sobre o tema.

Em sua palestra sobre o desempenho ambiental e energético de edifícios, o professor Simos Yannas destacou que atualmente há edifícios em Londres, uma cidade de clima temperado/frio, a consumirem mais energia com o uso do arcondicionado do que muitos edifícios em cidades de climas mediterrâneos, o que parece um contra-senso climático. Na formulação de uma crítica bastante provocadora ao ar-condicionado, o professor diz que esta é uma tecnologia do século 20 , servindo a edifícios do século 21 , apontando a cultura (e não a necessidade) do ar-condicionado como a grande barreira para a realização de projetos mais sustentáveis.

Dando continuidade à fala, foram apresentadas sete lições extraídas do estudo da arquitetura bioclimática nos trópicos, destacando edifícios no Rio de Janeiro: $1^{\mathfrak{a}}$, o alcance de condições de conforto ambiental por meio de espaços de transição; 2a, o uso de proteções solares e suficiente massa térmica como estratégias necessárias tanto para o edifício passivo (sem ar-condicionado) como para aquele concebido para o ar-condicionado, a fim de evitar flutuações indesejadas de temperatura; 3ạa a combinação de ventilação noturna e inércia térmica da construção como sendo uma lição clássica da arquitetura bioclimática 
dos trópicos, vantajosa por todo o ano, no caso de edifícios no Rio de Janeiro; 4a , o projeto de edifícios selados para o ar-condicionado como sendo completamente diferente, em forma e arranjos espaciais, daqueles que contemplam espaços abertos ao clima externo e espaços condicionados artificialmente. Para o segundo caso, é necessária uma combinação de espaços de transição entre o ambiente externo e aqueles condicionados, na busca da eficiência energética; $5 \stackrel{a}{a}$, a possibilidade da integração e um certo controle do usuário sobre suas condições ambientais como um fator fundamental para a satisfação dos ocupantes; 6므, observar o que os ocupantes aceitam e toleram em termos de condições ambientais e, com esta base, questionar normas nacionais e internacionais, assim, evitando os conceitos de "maximizar" ou "otimizar" condições ambientais e introduzir a idéia de condições adequadas; 7ạ, determinadas soluções de projeto são prejudiciais ao desempenho ambiental de edifícios em qualquer clima, como quando o edifício é envidraçado e reflexivo ou completamente transparente. Concluindo a palestra, o professor Simos Yannas disse que a questão da energia consumida na climatização de edifícios já ultrapassou os limites do universo da pesquisa em muitos países da Europa para ser uma questão de regulamentação e uma preocupação da prática arquitetônica.

A palestra sobre técnicas passivas de resfriamento de coberturas mostrou os principais pontos do projeto de pesquisa financiado pela Comunidade Européia, reunindo três instituições de pesquisa: Escuela Superior de Ingenieros, Universidad de Sevilla, na Espanha, Architectural Association Graduate School, em Londres, Reino Unido, e Desert Architecture Unit, no Jacob Blaustein Institute for Desert Research, Ben Curion University of the Negev, em Israel, que resultou na publicação e no software que levam o mesmo título: Roof cooling techniques: A design handbook. O objetivo da pesquisa foi explorar técnicas passivas de resfriamento de coberturas, incluindo resfriamento evaporativo e por radiação de ondas longas, visando ao melhor desempenho ambiental de ambientes internos em climas mediterrâneos. No contexto desta pesquisa, medições de modelos físicos auxiliaram na construção de um modelo matemático que deu origem à ferramenta de simulação computacional.

A terceira palestra teve foco na diversidade microclimática dos espaços externos e nas estratégias de projeto para a mediação de condições de desconforto. Três aspectos do ambiente construído foram apontados pelo professor como determinantes do microclima urbano: densidade construída, geometria da morfologia urbana e o desempenho térmico dos materiais que revestem as superfícies da cidade. Segundo o professor Yannas, assim como no estudo de caso de edifícios, a partir do estudo de espaços externos pode-se extrair uma série de lições para o projeto bioclimático. A exemplo disso, tratando-se do desenho vernacular de cidades de clima quente seco, como na Grécia, observa-se que ruas extreitas têm um efeito positivo no microclima, por dificultarem o acesso da radiação solar direta.

Estendendo a discussão, foi ilustrado pelo palestrante como as estratégias de sombreamento, a inserção de corpos d'água e de massas verdes, a geometria da morfologia urbana e dos espaços de transição e seus materiais são recursos do projeto urbano voltado para melhores condições ambientais. Ainda nessa 
palestra, o professor enfatizou a importância do estudo de espaços abertos no centro de quadras urbanas (courtyards), na criação de "oásis" microclimáticos para uso local, podendo ser conectados em uma rede de transformação do clima urbano. Ao final da palestra, o professor Simos Yannas chamou a atenção para o fato de a busca por cidades com microclimas urbanos mais amenos, confortáveis e convidativos ao uso público depender também de relações simbióticas entre os edifícios e os espaços abertos, no que se refere aos aspectos de projeto que influenciam o desempenho ambiental de ambos.

Em sua última palestra sobre o uso de ferramentas computacionais de simulação, o professor Yannas destacou que dentre as várias fases do projeto, os estudos de simulação os quais antecedem a concepção do projeto constituem o uso mais relevante dessa ferramenta, por mostrar o potencial do desempenho ambiental (conforto e eficiência energética) de diferentes soluções e, conseqüentemente, apontar caminhos para o partido arquitetônico. Ao longo do desenvolvimento do projeto, a simulação pode contribuir para o aperfeiçoamento do mesmo em prol de um melhor desempenho ambiental.

Em essência, a simulação computacional de desempenho ambiental tem seu valor maior em análises comparativas. Sendo assim, o professor chamou a atenção para a importância de contar com um caso de referência visando dar início a tais estudos e metas de desempenho para a avaliação final do projeto. Além disso, foi mencionado que medições in loco devem ser usadas para calibrar os resultados das simulações. Todavia, além da capacidade de fornecer resultados analíticos, o professor Yannas acredita que dentre as principais vantagens das ferramentas de simulação computacional do desempenho ambiental de edifícios está seu valor didático de demonstração dos fenômenos da física aplicada à construção.

O ensino de conforto ambiental e eficiência energética no programa da Architectural Association Graduate School, dirigido pelo professor Simos Yannas, evoluiu de uma fase com praticamente nenhuma ferramenta de simulação, há pouco mais de dez anos, para uma fase de vasta opção, chegando ao momento atual com um número reduzido, porém suficiente de softwares, utilizando-se os mais fundamentais. Dentre esses, o professor destacou o ECOTECT como o mais adequado para a geometria de insolação e o TAS, para o desempenho térmico de edificações.

O professor conclui sua palestra dizendo que se o interesse é aprender sobre o desempenho ambiental de edifícios, deve-se olhá-los para uso e operação e não para modelos abstratos (de simulação). No entanto, as simulações podem se tornar uma poderosa fonte de aprendizado quando correlações positivas podem ser extraídas entre simulações e edifícios. Em suma, as palestras do professor Simos Yannas mostraram uma aproximação entre o ensino de uma arquitetura bioclimática e a prática do projeto, reforçando o potencial de aprendizado por meio de estudos de caso, somados às técnicas de simulação computacional.

Com respeito à contribuição dos professores do Departamento de Tecnologia da FAUUSP para as discussões desse workshop, o Prof. Dr. Marcelo de Andrade Roméro, atual vice-diretor da faculdade, trouxe o tema: "Consumo de Energia no Brasil e Eficiência Energética na Arquitetura: Estudos de Caso na 
Cidade de São Paulo". Dando prosseguimento, a professora Denise Duarte apresentou as palestras: "O Grupo de Conforto Ambiental e Eficiência Energética da FAUUSP: Laboratório, Pesquisa, Ensino e Projeto"; e "Conforto Ambiental VI, Exercícios de Projeto para uma Arquitetura Bioclimática: Propostas Premiadas na Bienal Aroztegui de Idéias para a Arquitetura Bioclimática". A professora Joana Gonçalves apresentou "O Projeto de Ecoeficiência do CENPES II", Petrobrás, no Rio de Janeiro.

Concluindo, certamente a visita do professor Simos Yannas representou uma oportunidade de reflexão e atualização para aqueles interessados na pesquisa e no ensino de conforto ambiental e eficiência energética na arquitetura contemporânea. A reputação do curso de pós-graduação Environment and Energy tem fundamento em seu caráter exploratório de técnicas de ensino, no uso de ferramentas avançadas de simulação no processo de projeto e em uma atitude crítica e afirmativa perante a arquitetura, incluindo aqueles exemplos aclamados como sustentáveis ou eficientes energeticamente, aspectos esses evidenciados nas palestras do professor Simos Yannas.

Os eventos do workshop foram distribuídos entre os edifícios da FAUUSP na Cidade Universitária e na sede de sua pós-graduação, na rua Maranhão. A visita do professor Simos Yannas e a realização do workshop "Environment, Energy and Sustainable Design: Buildings and Urban Spaces" receberam auxílio financeiro da Pró-Reitoria de Pós-Graduação e do curso de pós-graduação da Faculdade de Arquitetura e Urbanismo da Universidade de São Paulo.

Mais informações sobre o Programa Environment and Energy da Architectural Association Graduate School são encontradas em "Sustainable Design in Architecture. The environment as form generator - Not a waste bin", texto do professor Simos Yannas, publicado na seção Depoimentos da revista Pós, n. 19, de junho de 2006.

\section{Joana Carla Soares Gonçalves}

Professora do Departamento de Tecnologia da Arquitetura da FAUUSP e pesquisadora do Laboratório de Conforto Ambiental e Eficiência Energética - LABAUT.

e-mail: jocarch@usp.br 